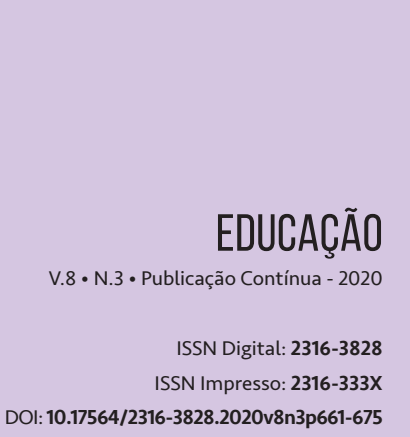

\section{FAMÍLIA E ESCOLA DA CRIANCSA COM DEFICIÊNCIA: UMA REVISÃO}

\section{FAMILIA Y ESCUELA PARA NINOS CON DISCAPACIDAD: UNA REVISIÓN}

Eliana Perez Gonçalves de Moura ${ }^{1}$ Adriane Cássia Silva Coitinho ${ }^{2}$ Neli Terezinha Costa ${ }^{3}$ Anna Regina Grings Barcelos ${ }^{4}$

\section{RESUMO}

Este artigo apresenta um estudo bibliográfico, do tipo revisão narrativa, com coleta de dados realizada a partir de fontes secundárias, cujo objetivo foi identificar e analisar dissertações e teses sobre os temas família, deficiência e escola. A coleta dos dados foi realizada em novembro de 2018 de forma on-line. 0 material foi selecionado na base de dados da Biblioteca Digital Brasileira de Teses e Dissertações (BDTD) a partir do cruzamento dos termos de busca em todos os campos. Os estudos aqui analisados nos instigaram a problematizar os desafios, contradições e percepções sobre o tema inclusão escolar, nos permitiram destacar alguns pontos críticos que ainda estão presentes nesse campo que se expressam, por exemplo, na falta comunicação entre as áreas médicas, sociais, psicológicas, pedagógicas e familiares, para que estes saberes se integrem, proporcionando avanços educacionais e de fato uma escola para todos.

\section{PALAVRAS-CHAVE}

Família. Escola. Criança. Deficiência. 


\title{
RESUMEN
}

Este artículo presenta un estudio bibliográfico, una revisión narrativa con recolección de datos de fuentes secundarias, cuyo objetivo fue identificar y analizar disertaciones y tesis sobre los temas familia, discapacidad y escuela. La recopilación de datos disponibles en Internet se realizó en noviembre de 2018. El material fue seleccionado de la base de datos de la Biblioteca Digital Brasileña de Tesis y Disertaciones (BDTD) por medio de los términos de búsqueda que se cruzaran en todos los campos. Los estudios analizados aquí nos instigaron a problematizar los desafíos, contradicciones y percepciones sobre el tema de la inclusión escolar y nos permitieron resaltar algunos puntos críticos que aún están presentes en este campo que se expresan, por ejemplo, en la falta de comunicación entre el campo médico, el social, el psicológico, pedagógico y familiar, para que este conocimiento se integre, proporcionando avances educativos y de hecho una escuela para todos.

\section{DESCRIPTORES}

Familia, Escuela, Niño, Discapacidad

\begin{abstract}
This paper presents a bibliographic study, an narrative review with data collection from secondary sources, whose objective was to identify and analyze dissertations and theses on the themes family, disability and school. Data collection was performed in November 2018 online. The material was selected from the database of the Brazilian Digital Library of Theses and Dissertations (BDTD) from the search terms crossing in all fields. The studies analyzed here instigated us to problematize the challenges, contradictions, and perceptions on the subject of school inclusion and allowed us to highlight some critical points that are still present in this field that are expressed, for example, in the lack of communication between the medical, social, psychological, pedagogical and family, so that this knowledge is integrated, providing educational advances and indeed a school for all.
\end{abstract}

\section{KEYWORDS}

Family. School. Child. Disability 


\section{INTRODUÇ̧̃̃o}

A partir do momento em que os pais têm a confirmação da chegada do bebê, fazem uma série de planos para o futuro do seu/sua filho/a. Na maioria das vezes, o projeto de vida dessa criança é idealizado, ainda antes de seu nascimento, envolve os sonhos e desejos da família no sentido de assegurar todas as oportunidades para que ela se desenvolva plenamente em todos os seus aspectos biopsicossociais. Por outro lado, conhecedores das dificuldades e estigmas que a pessoa com deficiência enfrenta diante de uma sociedade que ainda não oferece condições de acessibilidade e respeito à diversidade, a ideia intimida, tornando-se uma possibilidade que não é bem-vinda.

Nesse sentido, o diagnóstico da deficiência, obriga as famílias a descontruírem tudo o que haviam projetado para a vida da criança, demanda que pensem a paternidade/maternidade de uma forma diferente da planejada. Por conta disso, sentem-se confusas e inseguras frente às orientações de profissionais, opiniões e sugestões de pessoas próximas sobre o caminho que devem tomar para assegurar o desenvolvimento integral dos seus/suas filhos/as.

Além disso, sofrem com incompreensões e estigmas, tornando árdua a tarefa de ressignificar seus sentimentos, uma vez que estão diante de uma situação que sublinha a diferença da normalidade e a exceção. Diversos autores explicam que o nascimento de um bebê com alguma deficiência pode chocar os pais, frustrar seus sonhos ou desencadear reações e sentimentos como angústia, receio, desespero e até rejeição, que interferem na interação com o filho/a (OLIVEIRA, 2001; KLAUS; KENNELL; KLAUS, 2000).

Após seu nascimento, considerando a singularidade das necessidades especiais do bebê com deficiência, inicia-se uma nova etapa na qual os pais precisam encontrar alternativas para integrá-lo à família, o que se constitui em um processo de gradativa aceitação e adaptação. A deficiência impõe que as famílias empreendam esforços, inclusive, no que se refere a superação das barreiras sociais que se apresentam com maior intensidade a medida em que a criança inicia seu processo de escolarização, ainda que, historicamente, registram-se avanços nesse viés.

Nessa perspectiva, o tema deste estudo é a família e a escola da criança com deficiência, tem como objetivo compreender o âmbito da relação entre a família e a inclusão do/a estudante com deficiência na escola. Para isso foi realizado um levantamento bibliográfico na base de dados da Biblioteca Digital Brasileira de Teses e Dissertações (BDTD) sem limitação de período.

Ainda que a inclusão de estudantes com deficiência na escola represente uma temática preconizada por políticas públicas específicas e frequentemente problematizada entre os profissionais que se dedicam ao acompanhamento multidisciplinar do desenvolvimento dessas crianças e adolescentes, observa-se que na prática permanecem lacunas deixadas pela dificuldade na articulação das ações e ruídos na comunicação entre a família e a escola.

Por conseguinte, também a relevância desta pesquisa ao revisitar estudos sobre o tema, está relacionada ao fato de que atualmente, segundo o Ministério da Educação, 1,2 milhão de estudantes com deficiência, altas habilidades e transtornos globais do desenvolvimento estão matriculados em escolas regulares no Brasil. Assim sendo, contribuir para a garantia do acesso, permanência e quali- 
dade da educação de um elevado número de estudantes sempre é uma questão importante, em vista de se tratar de um direito humano fundamental.

\section{DEFICIÊNCIA E EDUCAÇ̃̃O ESPECIAL}

Desde as primeiras formas de organização sociais, os seres humanos perceberam que são diferentes entre si. Para Maior (2019, p. 31), “A diversidade manifesta-se, por exemplo, na distinção entre homens e mulheres, nas etapas do ciclo da vida e na própria fragilidade humana, fatores que podem determinar limitação no desempenho de algumas atividades”. Destaca ainda, que em todas as situações, identifica-se a supervalorização da capacidade física, sensorial e cognitiva, ou seja, a formação de padrões de normalidade, submetendo as pessoas com deficiência as mais diversas formas de discriminação, preconceito e desvalorização de suas vidas.

De acordo com Silva (1986, p. 21), “[...] anomalias físicas ou mentais, deformações congênitas, amputações traumáticas, doenças graves e de consequências incapacitantes, sejam elas de natureza transitória ou permanente, são tão antigas quanto a própria humanidade”. O conceito de deficiência e de espaço social ocupado por pessoas com deficiência, em um mesmo período histórico, foram concebidos pelas sociedades a partir de valores e princípios distintos. 0 autor cita, por exemplo, que enquanto na Alemanha nazista, as pessoas com deficiência eram submetidas a experiências científicas, nos EUA, os mutilados de guerra eram vistos como heróis, recebendo honrarias e tratamentos em instituições do governo.

No que se refere ao Brasil, o autor descreve que entre os séculos XVI e XVII as pessoas com deficiência eram chamadas de formas pejorativas tais como: mancos, aleijados, cegos, enjeitados ou surdos-mudos, especialmente, aqueles que pertenciam a população mais pobre. Trata-se de uma dimensão cultural que está em processo de transformação de hábitos, comportamentos e valores, que demanda das sociedades a quebra de paradigmas e o abandono de referências ancoradas no passado. Salienta-se que nas últimas décadas, visões distorcidas ou preconceituosas sobre as pessoas com deficiência foram ressignificadas em função do aumento da produção de conhecimento científico sobre o tema e com o surgimento de políticas públicas dedicadas a garantir os direitos, que também contribuem, de certa forma, para a mudança no modo de existir da sociedade.

Segundo Maior (2019, p.31), no decorrer do tempo entre a invisibilidade social e o reconhecimento dos direitos das pessoas com deficiência por meio de políticas públicas, o conceito de deficiência sofreu influências de [...] "uma longa trajetória representada pelas medidas caritativas e o assistencialismo, correspondentes a ações imediatistas e desarticuladas, que mantiveram as pessoas com deficiência isoladas nos espaços da família ou em instituições de confinamento".

A autora afirma que o conceito de deficiência pode ser compreendido a partir do modelo biomédico que surgiu na primeira metade do século XX ou por meio do modelo social, resultado das discussões realizadas na década de 1980, a partir da organização do Ano Internacional das Pessoas Deficientes (AIPD) pela Organização das Nações Unidas (ONU). No primeiro modelo, "as políticas públicas destinadas às pessoas com deficiência são específicas, isoladas e habitualmente restritas à saúde, assistência 
e educação especial em escolas segregadas" (MAIOR, 2019, p. 32). Em contrapartida, o foco do modelo social, são as condições de interação das pessoas com deficiência na sociedade visando a transformação das condições sociais, por meio de políticas públicas inclusivas (MAIOR, 2019).

As políticas públicas no Brasil elegem o modelo social como referência para a definição do conceito de deficiência, conforme está expresso no texto do Decreto $n^{0} 7612 / 2011$ que institui o Plano Nacional dos Direitos da Pessoa com deficiência - Plano Viver sem limites, no artigo $2^{\circ}$ - como: “[...] impedimentos de longo prazo de natureza física, mental, intelectual ou sensorial, os quais, em interação com diversas barreiras, podem obstruir a participação plena e efetiva na sociedade em igualdades de condições com as demais pessoas" (BRASIL, 2011, p. 1).

Por outro lado, segundo Arend (2009), no que tange a educação de crianças com deficiência, foi durante o governo de D. Pedro II, no século XIX, que foram criadas as primeiras escolas, mais especificamente para os surdos-mudos e os deficientes visuais. Naquela época, as pessoas utilizavam o termo "os especiais" para referirem-se aos deficientes físicos e mentais, para os quais não era permitida a educação junto às demais crianças consideradas normais. Neste cenário, somente ocorreram mudanças com o surgimento do movimento da Escola Nova, por volta da década de 1930, quando os professores escolanovistas introduziram nas escolas, testes de inteligência, o que foi uma forma de classificar e excluir estudantes considerados atrasados intelectualmente.

A primeira referência legal à educação especial, apresenta-se na Lei de Diretrizes e Bases da Educação (LDB) n 4024/61, no capítulo III, nos artigos, 88 e 89, Art. 88 - "A educação de excepcionais deve no que for possível, enquadrar-se no sistema geral de ensino, a fim de integrá-lo na comunidade"; Art. 89 - "Toda iniciativa privada considerada eficiente pelos conselhos estaduais, receberá dos poderes políticos, tratamento especial mediante bolsas de estudos, empréstimos e subvenções” (BRASIL, 1961).

Entretanto, foi a partir da homologação da Lei de Diretrizes e Bases para o ensino de $1^{\circ}$ e $2^{\circ}$ graus (Lei $\left.n^{0} 5.672 / 1971\right)$, que o ensino de crianças com deficiência passou a ser vinculada com a escola regular, como condição para o desenvolvimento da sociedade e não mais de forma isolada como na LDB 4.024/61 em que a Educação Especial era tratada de forma isolada e “excepcional”. (BRASIL, 1961, p.01).

Também entre os marcos da educação inclusiva no Brasil estão a Constituição Federal de 1988, que no seu inciso II do artigo 208 dispõe que o Estado deve assegurar a educação inclusiva aos estudantes com deficiência, preferencialmente no ensino regular e a última alteração da Lei de Diretrizes e Bases da Educação de 1996 que no seu inciso III, Artigo 4º estabelece o atendimento especializado gratuito aos estudantes com necessidades especiais, preferencialmente na rede regular de ensino (BRASIL, 1988; 1996).

No ano de 2014, o Plano Nacional de Educação (PNE), estabeleceu diretrizes e metas para a política nacional de educação até 2024. A meta de número 4 do PNE trata sobre a inclusão, seu objetivo é a universalização do acesso para a estudantes com deficiência na faixa etária de 4 a 17 anos, com diagnósticos de transtornos globais ou superdotação, do acesso à educação especializada preferencialmente na rede regular de ensino. Até 2018, segundo as estatísticas no site do PNE, a porcentagem de pessoas com deficiência matriculadas na rede regular de ensino era de $85.8 \%$. E a meta é chegar a 100\% até 2024. 
A Lei Brasileira de Inclusão da Pessoa com Deficiência, Lei n013.146, de 6 de julho de 2015, em seu Artigo 27, assegura o direito a educação da pessoa com deficiência ao longo de toda a vida, em todos os níveis de aprendizagem por meio de um sistema inclusivo que oportunize o seu máximo desenvolvimento biopsicossocial, ou seja de suas "[ ...] habilidades físicas, sensoriais, intelectuais e sociais, segundo suas características, interesses e necessidades de aprendizagem. (BRASIL, 2015, p. 19). Ainda no Artigo 28, destaca que cabe ao Estado:

II - aprimoramento dos sistemas educacionais, visando a garantir condições de acesso, permanência, participação e aprendizagem, por meio da oferta de serviços e de recursos de acessibilidade que eliminem as barreiras e promovam a inclusão plena; III - projeto pedagógico que institucionalize o atendimento educacional especializado, assim como os demais serviços e adaptações razoáveis, para atender às características dos estudantes com deficiência e garantir o seu pleno acesso ao currículo em condições de igualdade, promovendo a conquista e o exercício de sua autonomia; $\mathrm{V}$ - adoção de medidas individualizadas e coletivas em ambientes que maximizem o desenvolvimento acadêmico e social dos estudantes com deficiência, favorecendo o acesso, a permanência, a participação e a aprendizagem em instituições de ensino; VIII - participação dos estudantes com deficiência e de suas famílias nas diversas instâncias de atuação da comunidade escolar. (BRASIL, 2015, p. 20).

Nessa perspectiva, a escola inclusiva é aquela que garante a qualidade de ensino educacional a todas os estudantes, respeitando a diversidade e as potencialidades de cada um. Beyer (2006) entende que a concepção da educação inclusiva deve configurar-se em torno da desconstrução de processos de segregação da pessoa com deficiência, por meio de princípios bem definidos em seu projeto político pedagógico que possibilitem ao longo do caminho, revisões, redefinições e ressignificações. Neste sentido, o conceito de inclusão se expande do espaço escolar para o espaço social mais amplo, envolvendo as dimensões que constituem o contexto de vida das pessoas, compondo uma pedagogia com abordagem inclusiva positiva e afetiva.

0 autor acrescenta que a educação inclusiva tem seu princípio educacional fundamentado na heterogeneidade da classe escolar, envolvendo interações e aprendizagens entre crianças com situações singulares e diversas. As experiências múltiplas derivadas da evolução conceitual da educação inclusiva vêm resultando no amadurecimento do processo pedagógico no sentido de contemplar as demandas de alunos com necessidades especiais nas escolas de ensino.

\section{A FAMÍLIA E SUAS RELAÇ̃̃ES NO CONTEXTO SOCIAL}

Para Buscaglia (1997), a família é uma unidade social que tem influência na determinação do comportamento humano e no desenvolvimento da personalidade dos indivíduos. De acordo com o contexto social, Lévi-Strauss (1986), assinala que a família não é uma instituição natural, reforça a 
compreensão de que ela é socialmente constituída de acordo com as normas culturais e busca solucionar as demandas do seu cotidiano com base nas experiências passadas, na sua situação econômica, bem como nos legados étnicos, religiosos, entre outras influências.

Consequentemente, a família poderá apresentar dificuldades em cumprir seu papel de preparar seus/suas filhos/as para participarem ativamente da sociedade que, atualmente, enfatiza aspectos como eficiência e eficácia e que ainda, segundo Baumann (2010, p.10), "[...] vive uma nova época em que as relações sociais, econômicas e de produção são frágeis, fugazes e maleáveis, como os líquidos”.

Em abril de 2016, o Grande Dicionário Houaiss, em parceria com a Coordenadoria Especial de Diversidade Sexual (CEDS-RJ) deram início a um movimento, com a participação do público, para mudar a definição do verbete família no dicionário, tornando-o mais plural e fiel à realidade. Foi uma resposta ao Estatuto da Família, projeto de Lei (PL) 3.369, de 2015, aprovado pela Câmara dos Deputados, que reconhece apenas o núcleo formado a partir da união de um homem e de uma mulher5. Por meio do site oficial da ação, a equipe do Houaiss recebeu milhares de contribuições e realizou um somatório das opiniões, criando um significado que passou a ser descrito pelo seguinte texto: “[...] núcleo social de pessoas unidas por laços afetivos, que geralmente compartilham o mesmo espaço e mantêm entre si uma relação solidária».

De forma mais específica, Ferreira (2018, p. 138), define família como [..] “o conjunto de todos os parentes de uma pessoa, principalmente, dos que moram com ela, como os seus pais e irmãos, bem como as demais pessoas ligadas por laços afetivos".

Para Pimenta e Rabinovich (2006, p. 6), a família é onde são produzidas “[...] relações de cuidado entre seus membros por meio da proteção, da socialização, do afeto, do acolhimento, do respeito e potencialização do outro, bem como a transmissão de valores humanos". Ainda segundo as autoras, é na família que a criança estabelece os primeiros vínculos afetivos, inicialmente com a mãe, enquanto cuidadora e posteriormente com o pai, irmãos, avós ou pessoas que complementam a função materna. 0 desenvolvimento saudável desses vínculos a levará a ter autoconfiança, competência social, emocional e cognitiva, desenvolvendo sua independência e identidade.

Outrossim, Amiralian e Moraes (1986, p. 22), acrescentam que “a decisão de ter um filho está diretamente relacionada a realização de desejos dos pais, das suas necessidades e com as gratificações e recompensas que a criança poderá lhes trazer". Assim sendo, entende-se que o anúncio da chegada de um/uma filho/a que não foi planejado/a e com deficiência, sobrecarrega e tenciona ainda mais as relações intrafamiliares. Desse modo, terão que dar conta das questões de reorganização do seu espaço e tempo para acolher e integrar de forma inesperada um novo membro e lidar com os desafios ainda mais específicos relacionados ao desenvolvimento da criança com deficiência.

Em continuidade, as autoras sinalizam que o desenvolvimento da criança com deficiência depende da forma como a família irá reagir ao luto pela perda do/a filho/a idealizado, a negação da deficiência em virtude dos estigmas culturais, ao desapontamento pelas decisões já tomadas sobre o seu futuro, que não serão passíveis de realização e ainda a disponibilidade ou não de aporte financeiro para atender às suas necessidades específicas.

5 Previsão de revisão deste projeto de lei no ano de 2020. 
Segundo Buscaglia (2002, p. 23), o nascimento de uma criança com deficiência na família, coloca seus integrantes em conflito, uma vez que "[..] altera a dinâmica familiar, onde cada membro vivenciará de maneira particular a chegada dessa criança, podendo frustrar ou adiar projetos familiares e/ou pessoais". Nesta perspectiva, Pimental e Rabinovich (2006, p. 80), afirmam que a família [...] "tem a importante função de proporcionar a esta criança tornar-se sujeito desejante, uma pessoa que possa transformar seus impulsos em desejos, buscando realizá-los dentro do quadro de sua diferença e por meio dela”.

Declaram ainda, que a família é a primeira a sentir-se estigmatizada, necessitando para se reestruturar de uma rede de apoio de familiares, amigos, políticas públicas (orientação, atendimento e acompanhamento) que podem auxiliá-la a acreditar na sua capacidade de cuidar e educar seu/sua filho/a, buscando oportunidades e estratégias para a superação das barreira sociais que irão ser exigentes, em todas as áreas do desenvolvimento humano e principalmente no convívio social.

Em continuidade, Fiamenghi Jr. e Messa (2007), declaram que [...] “a rede de apoio e os serviços disponibilizados para tratamento e acompanhamento da pessoa com deficiência parecem favorecer a adaptação da família, que necessita ser atendida com recursos e profissionais adequados". A temática é ampla, complexa e extrapola os limites deste estudo, porém, em que pesem esses contornos, acredita-se que as dificuldades estão associadas a diversidade das organizações familiares, bem como a relação com o contexto social onde estão inseridas e a sua articulação com os equipamentos comunitários que integram as políticas públicas de assistência social, saúde e educação.

\section{PROCEDIMENTOS METODOLÓGICOS}

Trata-se de um estudo de levantamento bibliográfico, do tipo revisão narrativa, com coleta de dados realizada na base de dados da Biblioteca Digital Brasileira de Teses e Dissertações (BDTD), em novembro de 2018, com o objetivo de identificar e analisar dissertações e teses sobre os temas família, deficiência e escola a fim de compreender como vem sendo abordada a relação entre a família e a inclusão do/a estudante com deficiência na escola.

Para o desenvolvimento do estudo, foram seguidas as etapas metodológicas constituídas desde o estabelecimento dos critérios de inclusão e exclusão, seleção da amostra, definição das informações extraídas dos estudos selecionados, organização e apresentação dos estudos em formato de quadro, apresentação, análise e discussão dos resultados (MENDES; SILVEIRA; GALVÃO, 2008).

A pesquisa na referida base de dados foi realizada a partir dos descritores "família"; "deficiência" e "escola". Como critérios de inclusão foram eleitos: a) o texto ser redigido em português; b) publicações disponibilizadas integramente e on-line; c) sem limitação de período. Por outro lado, como único critério de exclusão, optou-se por desconsiderar para análise os textos não pertinentes a temática.

Aplicados os critérios de inclusão e exclusão foram selecionadas três dissertações e uma tese, envolvendo a temática família e inclusão escolar de crianças com deficiência. 
Os estudos selecionados foram organizados a partir de uma matriz de execução e analisados na íntegra, com o intuito de responder ao objetivo geral da revisão. O Quadro 1, abaixo apresentado, classifica as informações sobre o material empírico:

Quadro 1 - Trabalhos temática família, inclusão, deficiência

\begin{tabular}{|c|c|}
\hline Nivel & Ano \\
\hline Tese & 2009 \\
\hline Dissertação & 2013 \\
\hline Dissertação & 2013 \\
\hline Dissertação & 2017 \\
\hline
\end{tabular}

Fonte: material empírico

Os resultados obtidos serão apresentados de forma descritiva e discutidos à luz das referências adotadas para este estudo.

\section{DISCUSSÃO DOS RESULTADOS}

A partir do seu objetivo geral, considerando-se os estudos selecionados, emergem as seguintes categorias: a) trajetória das famílias para inclusão das crianças com deficiência na escola (BRITO, 2017; BAZON, 2009); b) percepções das famílias sobre o processo de inclusão escolar (CRUZ, 2013; JONES, 2013).

O estudo de Brito (2017), apresenta como objetivo caracterizar as necessidades dos familiares de estudantes com deficiência no processo de escolarização em uma rede regular de ensino. Seus resultados apontam para um perfil de famílias numerosas, de baixo poder aquisitivo, com pouca escolaridade e sem qualificação profissional. Ainda, que entre as principais demandas dessas famílias, a mais evidente, é a necessidade de receber informações e de acompanhamento profissional.

Em relação às estratégias de adaptação da família, o pesquisador levantou que, mais de 35 familiares entre os 59 entrevistados, afirmam que realizaram e/ou realizam mudanças em seu estilo de vida para se adaptar a condição de ter uma criança com deficiência em sua família assim como para que este o microssistema familiar continue funcionando de modo harmônico. Outro fato que merece destaque, faz referência ao enfretamento de adversidades, visto que $62,7 \%$ dos entrevistados afirmaram que se sentem preparados e dispostos a enfrentar qualquer dificuldade em relação a proteção, saúde e educação do seu/sua filho/a com deficiência.

Com o objetivo de compreender a percepção da família da criança com deficiência sobre o processo de inclusão de seus/suas filhos/as no contexto das salas comuns da educação infantil, Cruz (2013), realizou entrevistas semiestruturadas com quatro famílias, incluindo todos os seus integrantes. Os resultados levantados pelo pesquisador indicam que a falta de informações sobre o diagnós- 
tico, eleva ainda mais o grau de insegurança dos pais em relação a educação de seus/suas filhos/ as. Neste contexto, o pesquisador indica que algumas famílias possuem dificuldades em aceitar um diagnóstico de deficiência, o que pode influenciar as relações familiares.

Além disso, identifica um despreparo por parte da comunidade médica tanto em informar o diagnóstico, quanto em oferecer um acompanhamento a essas famílias. 0 pesquisador, observa ainda, que as famílias vivenciam sentimentos de angústia e apreensão quanto ao futuro social e escolar da criança, ainda que entendam, a experiência escolar de seus/suas filhos/as como algo positivo. Por fim, a pesquisa aponta que a compreensão do conceito de inclusão pelas famílias não se articula àquele preconizado nas políticas de educação inclusiva, sugerindo o desconhecimento das mesmas, conforme também apontado por Brito (2017).

Igualmente, Buscaglia (1997), destaca que mesmo depois do impacto inicial, a presença de uma criança com deficiência exige que o microssistema familiar se organize para atender necessidades específicas. Esse processo pode durar dias, meses ou anos e mudar o estilo de vida da família, seus valores e papéis. A flexibilidade com que a família irá lidar com a situação depende das experiências prévias, aprendizado e personalidade dos seus membros.

O estudo de Jones (2013), buscou identificar as ações de inclusão social por meio da percepção dos familiares e educadores de crianças com deficiências múltiplas em escolas de ensino regular. Demonstra em seus resultados que a maioria dos/as professores/as não possui experiência para ensinar crianças com deficiência e que há necessidade de apoio em sala de aula, visando atender às necessidades educacionais especiais destes estudantes. Os relatos das entrevistas e das observações em sala de aula apontam fatores importantes no que diz respeito ao processo inclusivo social das crianças com deficiências múltiplas, demonstrando incompatibilidade entre os relatos dos familiares com as observações realizadas, em relação ao acolhimento, atendimento e metodologia de ensino.

Além disso, aspectos de exclusão social foram evidenciados no cotidiano de determinados estudantes observados/as. Diante deste cenário, a pesquisa de Jones (2013) propõe algumas sugestões direcionadas às instituições de ensino, com a intensão de promover a superação das dificuldades identificadas, tais como:

Buscar conhecer e compreender o diagnóstico das crianças com deficiência matriculadas na escola, bem como o seu processo de acompanhamento pelas equipes multiprofissionais;

Redução de número de estudantes em sala de aula, adequando-se aos marcos legais norteadores da educação especial;

Disponibilização de materiais específicos e diferenciados para cada estudante com deficiência ampliação da e oferta de cursos de capacitação para os/as professores/as;

Qualificação da comunicação entre os/as profissionais que realizam atendimento pedagógico especializado e os professores/as titulares das turmas regulares sobre os materiais utilizados e o trabalho que está sendo desenvolvido, para que estes recursos sejam utilizados, também, em sala de aula, posicionar os/as estudantes com deficiência no meio da sala de aula e não isolados, como nas fileiras extremas, possibilitando, assim, maior interação com os colegas.

Bazon (2009), buscou por meio de sua pesquisa, identificar como a inclusão escolar da criança com deficiência visual é influenciada pelas relações familiares. Evidenciou o papel fundamental da interação entre a família e escola da criança com deficiência, ressaltando que as famílias ao estabe- 
lecerem atitudes cooperativas favorecem a inclusão. Nesse sentido, os resultados de Bazon (2009) corroboram Buscaglia (1997, p. 23) quando o autor afirma, que:

[...] a família é uma força social que tem influência na determinação do comportamento humano e na formação da personalidade. A família é o lócus da interdependência; os relacionamentos estabelecidos entre os familiares influenciam uns aos outros e toda mudança ocorrida nesse sentido irá exercer influência em cada membro individualmente ou no sistema como um todo.

Da mesma forma, atitudes de abertura e disponibilidade para atender às necessidades específicas dos/as estudantes com deficiência por parte da escola, são fundamentais para a sua interação e desenvolvimento. Contudo, a maioria dos familiares revelam-se satisfeitos com a escola e os/as professores/as, mostrando o desejo de contribuir com o processo de ensino para o melhor desenvolvimento de seus filhos. Trata-se de uma relação profícua na qual a escola funciona como um apoio aos familiares que não tem com quem contar para ajudá-los. Nesse sentido, Brito (2017) e Cruz (2013) declaram que os pais reconhecem os benefícios e a contribuição da escola regular para o desenvolvimento das habilidades e potencialidades das crianças com deficiência

A análise dos estudos, também evidenciou que a inserção do/a estudante com deficiência na escola modifica significativamente a dinâmica familiar por meio de novas perspectivas acerca do desenvolvimento da criança. Por outro lado, atitudes de preconceito, barreiras atitudinais e déficit na formação de professores afetam de forma negativa o processo de inclusão.

Os estudos demonstram que a escola regular, quando inclusiva, representa a garantia de acesso, participação e aprendizagem de todos/as os/as estudantes com deficiência, bem como o seu entrelaçamento com as demais políticas públicas rompe paradigmas sobre a compreensão da educação especial. Nessa perspectiva, a família pode encontrar na qualidade da sua relação com a escola as referências e o incentivo necessário para promover a evolução de seu/sua filho/filha em todas as áreas do seu desenvolvimento.

\section{CONSIDERAÇÕES FINAIS}

A presente revisão narrativa buscou elaborar um mapeamento de estudos, envolvendo informações que nos proporcionassem maior compreensão e reflexão no que se refere a relação entre a família e a inclusão do aluno com deficiência no ambiente escolar. A relevância e complexidade das relações família e escola de ensino regular para o processo de inclusão impulsiona o desenvolvimento de estudos no campo da diversidade cultural e inclusão social.

Desse modo, os estudos aqui analisados nos instigaram a problematizar os desafios, contradições, percepções sobre o tema inclusão escolar e nos permitiram destacar alguns pontos críticos que ainda estão presentes nesse campo que se expressam, por exemplo, na falta comunicação entre as áreas médicas, sociais, psicológicas, pedagógicas e familiares, para que estes saberes se integrem, 
proporcionando avanços educacionais e de fato uma escola para todos. A preocupação com as condições educacionais para o desenvolvimento de crianças com deficiência deu sentido ao estudo junto às famílias, permitindo compreender e identificar as mútuas influências exercidas entre escola e família no processo de inclusão escolar e social.

Destaca-se a importância da escola estar aberta e disponível para atender as necessidades especificas dos estudantes com deficiência, fazendo a diferença na inclusão e desenvolvimento destes. Nesse sentido, os resultados dos estudos analisados apontam para uma certa satisfação dos familiares com a escola e professores, desejando contribuir com ela para o desenvolvimento dos seus filhos/as. E que a possibilidades de aproximação entre escola e família apresenta benefícios os seus filhos/as.

\section{REFERÊNCIAS}

AMIRALIAN, Maria Lucia Toledo Moraes. Psicologia do excepcional. São Paulo: Editora Pedagógica e Universitária, 1986. Disponível em: https://repositorio.usp.br/item/000754022. Acesso em: jul. 2020.

\section{AREND, Catia Alire Rodrigues; MORAES, Valdete Aparecida Veiga de. A historicidade de} educação especial da década de $\mathbf{1 9 6 0}$ até dias atuais. Disponível em: http://www.uel.br/eventos/ congressomultidisciplinar/pages/arquivos/anais/2009/029.pdf. Acesso em: jul. 2020.

\section{BAZON, Fernanda Vilhena Mafra. As mútuas influências, família-escola, na inclusão escolar de} crianças com deficiência visual. 2009. Tese (Doutorado em Educação) - Faculdade de Educação, Universidade de São Paulo, São Paulo, 2009. doi:10.11606/T.48.2009.tde-14122009-10293.

BEYER, O. Da integração escolar à educação inclusiva: implicações pedagógicas. In: BAPTISTA, C. R. (org.). Inclusão e escolarização: múltiplas perspectivas. Porto Alegre: Mediação, p. 73-81. 2006.

BRADT, J. O. Tornando-se pais: famílias com filhos pequenos. In: CARTER, B.; MCGOLDRICK, M. As mudanças no ciclo de vida familiar: uma estrutura para a terapia familiar. Tradução de Maria Adriana Veríssimo Veronese. 2. ed. Porto Alegre: Artmed, 1995.

BRASIL Lei no 4.024/61 de 20 de dezembro de 1961. Fixa as Diretrizes e Bases da Educação

Nacional. Disponível em: http://www.planalto.gov.br/ccivil_03/leis/l4024.ht. Acesso em: nov. 2020.

BRASIL. Constituição da República Federativa do Brasil. Senado Federal. Brasília, DF: Centro Gráfico, 1988. 292 p.

BRASIL. Lei n 8.069, de 13 de julho de 1990. Estatuto da Criança e do Adolescente. Câmera dos Deputados. DOU de 16/07/1990 - ECA. Brasília, DF, 1990. 
BRASIL. Estatuto da pessoa com deficiência. Brasília: Senado Federal, Coordenação de Edições Técnicas, 2015. 65 p. Disponível em: http://www.planalto.gov.br/ccivil_03/_ato2015-2018/2015/lei/ 113146.htm . Acesso em: dez. 2018.

BRITO, Dorca Soares de Lima. Famílias de crianças com deficiência e a escola comum: necessidades dos familiares e construção de parceria. 2016. Dissertação (Mestrado em Educação) PPG em Educação, Universidade Federal da Grande Dourados, Grande Dourado, MS, 2016.

BUSCAGLIA, L. Os deficientes e seus pais. Tradução de Raquel Mendes. 3. ed. Rio de Janeiro: Record, 1997.

CRUZ, Daniela Messa e Melo. $\mathbf{O}$ que a família de crianças com deficiência tem a nos dizer sobre a inclusão escolar de seus filhos? 2013. Dissertação (Mestrado em Educação) - Centro de Educação Diversidade e Pratica Educacionais, Universidade Federal do Espírito Santo, Vitória, ES, 2013.

DELMORE-KO, P.; PANCER, S. M.; HUNSBERGER, B.; PRATT, M. Becoming a Parent: Relation between Prenatal Expectations and Postnatal Experience. Journal of Family Psychology, Washington, DC: APA, v. 14, n. 4, p. 625-640, 2000.

DIAS, Maria Berenice. Manual de direito das famílias. 4. ed. São Paulo: Revista dos Tribunais, 2005.

ENGELS, F. A origem da família, da propriedade privada e do Estado. 10. ed. Rio de Janeiro: Civilização Brasileira, 1985.

FERREIRA, Aurélio Buarque de Holanda. Dicionário Eletrônico Aurélio Século XXI. Rio de Janeiro: Editora Nova Fronteira e Lexikon Informática, 2018. Disponível em: https://www.dicio.com.br/ familia/ .Acesso em: jul. 2020.

HOUAISS, Antônio. Dicionário Houaiss da Língua Portuguesa. Rio de Janeiro, Ed. Moderna, 2016.

JONES, Andreza Batista. Percepção da inclusão social na visão da família e educadores de crianças com deficiências múltiplas. Dissertação (Mestrado em Distúrbios do Desenvolvimento) Departamento de Psicologia, Universidade Presbiteriana Mackenzie, São Paulo, SP, 2013.

KLAUS, M.; KENNELL, J.; KLAUS, P. Vínculo: construindo as bases para um apego seguro e para a independência. Porto Alegre: Artes Médicas, 2000.

LÉVY-STRAUSS, Claude. Minhas palavras. São Paulo: Brasiliense. 1986. 
MAIOR, Izabel Maria Madeira de Loureiro. Movimento político das pessoas com deficiência: reflexões sobre a conquista de direitos. Revista Inclusão e Sociedade. Distrito Federal, v. 10. No 02. P. 28-36, 2017. Disponível em: file:///C:/Users/User/Downloads/4029-Texto\%20do\%20 artigo-11669-1-10-20171201.pdf. Acesso em jul. 2020.

MENDES, Karina D. S.; SILVEIRA, Renata C. C. P.; GALVAO, Cristina M. Revisão integrativa: método de pesquisa para a incorporação de evidências na saúde e na enfermagem. Texto \& Contexto - Enfermagem, Florianópolis, v. 17, n. 4, p. 758-764, dez. 2008. Disponível em: https://www.scielo.br/scielo.php?script=sci_ arttext\&pid=S0104-07072008000400018\&lng=en\&nrm=iso Acesso em: nov. 2018.

OMS - Organização Mundial da Saúde. Classificação Internacional de Funcionalidade, Incapacidade e Saúde (CIFIS). Centro Colaborador da Organização Mundial da Saúde para a Família de Classificações Internacionais, org.; coordenação da tradução Cassia Maria Buchalla. São Paulo: Editora da Universidade de São Paulo - EDUSP; 2013. Disponível em: http://www.fsp.usp.br/cbcd/ wp-content/uploads/2015/11/Manual-Pra\%CC\%81tico-da-CIF.pdf. Acesso em: jul. 2020.

ONU - Organização das Nações Unidas. Declaração dos direitos das pessoas deficientes.

Disponível em: http://portal.mec.gov.br/seesp/arquivos/pdf/dec_def.pdf . Acesso em: ago. 2019.

SILVA, Otto Marques da. A epopeia ignorada: a pessoa deficiente na história do mundo de ontem e de hoje. São Paulo: CEDAS,1986. Disponível em: https://issuu.com/amaurinolascosanchesjr/docs/a-epopeia-ignorada-oto-marques-da-. Acesso em nov. 2019 
1 Doutora em Educação; Professora do Programa de Pós-graduação em Diversidade Cultural e Inclusão Social, Universidade Feevale. E-mail: elianapgm@feevale.br

2 Licenciada em Pedagogia; Mestranda em Diversidade Cultural e Inclusão Social, Universidade Feevale. E-mail: adriane.orientadora@gmail.com

3 Mestre em Diversidade Cultural e Inclusão Social, Universidade Feevale; Psicóloga. E-mail: nelicosta.psi@gmail.com

4 Educadora Física; Mestranda do Programa de Pós-graduação em Diversidade Cultural e Inclusão Social, Universidade Feevale. E-mail: annaggrings@gmail.com

\section{(ㅇ) (1) (-)}

Este artigo é licenciado na modalidade acesso abertosob a Atribuição-Compartilhalgual CC BY-SA

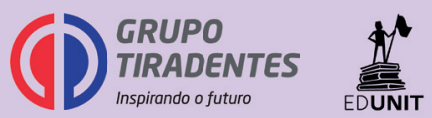

